\title{
De Victor à educação especial: ainda o corpo selvagem?
}

Rafael Siqueira de Guimarães*

\section{Resumo}

Este ensaio tem o intuito de refletir sobre os Relatórios produzidos por Itard (1822, 1828) como documentos que enunciam sobre o olhar perplexo sobre a diferença, compreendendo-o como possibilidade de elencar questôes sobre o momento histórico em que foi produzido, no que tange à educaçáo e como conectá-lo com questôes da atualidade nas propostas direcionadas à Educação Especial. Foram realizadas análises que visaram tensionar uma questão importante para a Educação Especial ainda hoje, que é a dimensão do governo do corpo e suas relações com o preconceito e o estigma. Para tanto, realizei um diálogo profícuo com a produção de Lígia Assumpção do Amaral, cujo tema de pesquisa sempre foi a construção cultural do corpo deficiente, bem como com o campo de estudos do discurso. Como conclusáo, observamos que, no contemporâneo, ainda a Educação Especial é filiada a estas questôes: acredita na resiliência, na norma e na funcionalidade-instrumentalidade da vida.

Palavras-chave: Análise histórico-social das diferenças; Discurso; Itard.

* Professor doutor da Universidade Federal do Sul da Bahia, Itabuna, Bahia, Brasil. 


\section{From Victor to Special Education: the wild body, yet?}

\section{Abstract}

This essay has the objective to reflect about the reports produced by Itard (1822, 1828), like documents that express about the bewildered look about the difference, analyzing it like possibility to arrange questions about the historic moment that was produced about education and connect with actual questions on Special Education proposes. Analyses were performed that aimed to confront an important question to Special Education today, the government of the body and its relations with prejudice and stigma. I realized a profitable dialogue with Lígia Assumpção do Amaral's production, that studied the cultural construction of deficient body, as well as the discourse studies' camp. Concluding, we observes that, on contemporary, the Special Education is still affiliated to these questions: beliefs in the resilience, in standard and in funcionality-instrumentality of life.

Keywords: Historical and social analysis of differences; Discourse; Itard.

A narrativa do encontro de Victor e Itard muito interessou a filósofos, cientistas e as pessoas comuns na Paris da passagem do século XVIII para o Século XIX e trouxe diversas indagaçôes sobre questóes muito importantes para a filosofia e para os processos de ensino-aprendizagem, especialmente no que diz respeito às correntes inatistas e empiristas, às relaçôes entre natureza e cultura e aos problemas metodológicos para a Educação e, mais especificamente, para a Educaçáo Especial. É evidente que este acontecimento histórico, devido ao interesse do próprio Itard e, especialmente, de seus procedimentos orientados pelo entendimento de que as deficiências do menino foram resultado de sua privação social, possibilitaram a emergência de uma Educação Especial, o que já pode ser percebido na própria caminhada do médico posteriormente ao trabalho com Victor.

Neste ensaio, buscarei desenvolver algumas reflexôes a partir da leitura dos relatórios que visarão tensionar uma questão importante para a Educação Especial ainda hoje, que é a dimensão do governo do corpo e suas relaçôes com o preconceito e o estigma. Esta dimensão muito foi discutida especialmente no trabalho de uma pesquisadora brasileira, expoente para a área, Lígia Assumpção do Amaral, durante sua trajetória acadêmica e de vida e, portanto, tomarei como base alguns de seus trabalhos, entendendo-a como uma interlocutora neste processo, apoiando-me em alguns de seus estudos e amplificando-os a partir de leituras outras realizadas. Os relatórios sobre Victor dizem de um sujeito e me interessa saber de que sujeito se fala, pois isto se relaciona diretamente a como a Educação Especial, desde então, compreende este sujeito em seu processo de definição de objetivos e estratégias metodológicas.

Minhas questôes norteadoras principais para as interlocuções que aqui proponho são: Quais os espaços de fala (e de silenciamento) foram produzidos durante este processo? Em que medida algumas dimensôes da vida são mais importantes que outras na Educação Especial? 
Ao dialogar com o caminho de estudos que tenho perseguido na minha trajetória e na interlocução com outros estudos, meu objetivo, neste ensaio, é dimensionar este momento histórico e suas relaçóes com a Educação Especial na contemporaneidade.

Itard propóe como primeira meta de educação ao menino selvagem, "interessá-lo pela vida social, tornando-as mais amena do que aquela que ele então levava, e sobretudo, mais análoga à vida que acabava de deixar." (BANKS-LEITE; GALVÃO, 2000, p. 135). "Interessá-lo à vida social", na proposta de Itard, consistiu em, primeiramente, acompanhá-lo em seu "modo de vida" para, a partir daí, paulatinamente, introduzi-lo ao processo educativo civilizatório, promovendo uma interação sucessiva do menino com o meio.

O olhar perplexo dos "curiosos de Paris", como menciona Itard, frente ao comportamento pouco aceitável socialmente foi reforçado pela brusca mudança em sua forma de vida: ele recebeu maus-tratos, teve convivência forçada com outras crianças e foi muito importunado pelos citadinos parisienses. Como aponta Amaral (1994a, p. 247), "o olhar reconhece o corpo diferente - porque, de qualquer forma, corpo, mas reconhece-o simultaneamente como desviante e, portanto, estranho, incômodo, assustador. Tal como o corpo do monstro".

Este olhar que estranha o menino selvagem vai desde aos maus-tratos até à iniciativa educacional de Itard: levá-lo a uma civilidade para que possa conviver com a norma social. Por mais que, antes disso, a posição em relação à "idiotia" do menino fosse de compreendê-la como questáo biológica inata e que nada poderia se fazer, a perspectiva do estranhamento ainda permanece: para o médico, é necessário que este rapaz, nesta época, tenha necessariamente que viver de acordo com as normas. "De qualquer forma, corpo" estabelece uma relação direta com a norma. Reconhece-se um corpo humano, um sujeito que pode e deve ser objetificado a partir do que se estabelece como norma. Reconhece-se o corpo do menino como "o antigo pertencimento a um grupo - do sangue, da tradição, de ligaçáo entre aqueles da mesma altura ou da mesma baixeza" (FOUCAULT, 1996, p.20) e táo logo, por ser esse semelhante a tantos outros meninos, só pode entấo ser superfície de governo, de controle, de disciplinamento.

As táticas utilizadas por Itard não são baseadas na crueldade física, pois não impóem ao menino o convívio forçado ou maus-tratos: "teria sido tanto inútil quanto desumano contrariar estes últimos hábitos, e entrava mesmo em minhas metas associá-los à sua nova existência, para deixá-la mais agradável" (BANKS-LEITE; GALVÃO, 2000 , p. 139, grifo meu). Mas, de que "nova existência" ele nos fala que não a existência da norma? A subjetividade de Victor, adjetivada de tantas interpretaçóes, de "selvagem" a "indolente"? Esta subjetividade "adjetivada" se reflete nas práticas profissionais ainda hoje da Educação Especial, como aponta Amaral (1994b), que percebe a presença do aspecto "selvagem" no entendimento dado ao sujeito com deficiência. 
Como nos refere Nogueira (2015):

Não é a psiquiatrização, por óbvio e a princípio, o que normaliza, mas há um dispositivo pedagógico psiquiatrizante que, paradoxalmente, ao anormalizar, é o que permite garantir a ação das biopolíticas inclusivas, pois atua na captura da diferença, orquestrando o reajuste dos corpos e os reinserindo em novas normalidades. (NOGUEIRA, 2015, p. 76).

Está, ainda nas tentativas supostamente bem intencionadas de Itard, o cerne das proposiçóes que de um lado rompem com as perspectivas inatistas sobre a deficiência, mas que, por outro, constroem um caminho possível a uma perspectiva educacional que, por ainda basear-se no entendimento da necessidade da normatizaçáo, propóe metodologias e processos de governo destes corpos. Como nos diz Amaral (1994b, p. 78), “a vigilância é necessária e é legítima”. Legítima porque, retomando a mesma autora (AMARAL, 1994a), ainda que desviante, é corpo. A base, ainda impregnada na perspectiva da educação para o selvagem Victor, é sua essência biológica: se humano, deve agir como um humano.

Sob a égide da humanização deste corpo - e, se humano, logo educável, foram e ainda são, nas práticas da inclusão - feitas interpretaçôes como as da observação das expressôes do jovem "desafortunado": "em certos casos elas pareciam reproduzir a expressão calma da saudade e da melancolia” (BANKS-LEITE; GALVÃO, 2000, p. 139). Vejamos: um ser humano, digno dos mais belos sentimentos humanos, mas que só sabia comer, dormir e correr há que estar disposto a uma educação que o inclua na norma, para que ele possa estar apto a aproveitar de todas as possibilidades que o mundo moderno o proporcionaria, caso deixasse de ser "selvagem". Isto seguiu à empreitada de Itard em desenvolver as sensaçôes:

\begin{abstract}
Abstraindo-se alguns casos como este, em que a falta de atenção da parte da alma uma falta de sensibilidade no órgão, achava-se contudo que esta propriedade nervosa era singularmente fraca na maior parte dos sentidos. Em consequência, entrava em meu plano desenvolvê-la por todos os meios possíveis e preparar o espírito para a atenção dispondo os sentidos para receber impressóes mais vivas. (BANKS-LEITE; GALVĀO, 2000, p. 142).
\end{abstract}

$\mathrm{Na}$ época Itard coloca em xeque a perspectiva inatista defendida por Pinel e outros psiquiatras ao propor procedimentos educativos que favorecessem, mesmo que frente à uma impossibilidade orgânica - ainda que náo pudesse se comprovar! - o desenvolvimento das funçóes sensoriais para que Victor percorresse o, mesmo que longo, caminho de educação, e fosse incluído entre os seres civilizados. Como se observa nos relatórios, foi-lhe ensinado a experimentar alimentos que as crianças de sua época mais desejavam, entretanto, "a aversão que ele demonstrou por todas as substâncias doces e por nossas mais delicadas iguarias foi insuperável" (BANKS-LEITE; GALVÂO, 2000, p. 149).

O que teria sentido o jovem Victor à sua exposição programada pelo educador a todos esses procedimentos? Como eles foram lidos por Itard? Em que medida produziu-se e continuamente se produzem silenciamentos dos sujeitos da educação especial? 
Como Lígia nos aponta em sua Tese de Livre Docência, sobre a sua experiência de vida com a deficiência: "[...] Sofrimentos e superaçôes. Enfrentamentos e acolhidas. E lá estava ela, ora figura, ora fundo" (AMARAL, 1998, p. 14). Em que medida, o espaço das relaçóes pessoais calcadas na educabilidade proposta por Itard o assujeitou à normatização? Em que medida estes procedimentos, embasados por estes discursos de uma normatização e inclusão humanizada ainda permanecem na perspectiva da educação das pessoas com deficiência?

A inclusão tem dono e tem foco. O discurso contemporâneo da resiliência, como aponta Nogueira (2015) pode ser uma possibilidade de interlocução: a sobrevivência às questóes adversas vividas por Victor seriam superadas por procedimentos educacionais: mesmo que ele não fosse civilizado, poder-se-ia ensiná-lo questóes básicas para a vida dentro da normalidade civilizada; mesmo que seus órgãos do sentido não estivessem amplamente desenvolvidos, poder-se-ia dar-lhe a oportunidade de ter uma "nova vida", repleta de emoçóes mais avivadas, pois, estas, de fato, chegariam à sua alma, que é, pois, humana. É, pois, educável.

Os estudos de Itard, a se considerarem sua época, questionam o lugar de soberania organicista no tratamento das deficiências quando assume repetidamente que os percalços encontrados no processo mais se relacionam com os procedimentos adotados que com questóes orgânicas de Victor. Este, sem dúvida, foi um passo muito importante. Entretanto, sob a égide dos fazeres pedagógicos, outros vieses para a normatizaçáo e o controle se instauram, e que, posteriormente, se configuraram em perspectivas inclusivas "humanizadoras".

Se Victor dispóe de um corpo que pode ser humanizado pelo processo educacional, logo tem o direito da fala. É a fala, uma das expressóes da língua materna francesa que, no Século XVIII, torna-se a língua da liberdade (HAGËGE, 1996), que apenas no século XIX passou a ser língua da maioria, por sua inserção definitiva nas escolas. A Revolução Francesa e seu ideário de liberdade está muito presente nas intençóes de Itard - e do governo que decide pelo financiamento econômico de seus projetos educativos para Victor - e, portanto, ensinar a língua materna (francesa) faz parte deste projeto. É importante observar que, em seu trabalho posterior a Victor, na Educação de Surdos-Mudos, Itard dedicou-se ao oralismo como procedimento metodológico: uma oralidade francesa, esta língua da liberdade na aurora do século XIX.

Em seu questionamento "o selvagem fala? Se não é surdo, por que não fala?" (BANKS-LEITE; GALVÃO, 2000, p. 153), Itard, baseando-se numa ideia de desenvolvimento da linguagem relacionada a um desenvolvimento da percepção auditiva, busca observar e perceber qual o grau de sua audição - especialmente do ponto de vista qualitativo - para desenrolar um processo de ensino que vá desenvolvendo a escuta de Victor. Primeiramente, faz os seguintes comentários:

É fácil imaginar que no meio das florestas e longe do convívio com qualquer ser pensante, o sentido da audiçáo de nosso selvagem não experimentasse outras impressóes senão as que faziam nele um pequeno número de ruídos e, particularmente, aqueles ligados às suas necessidades físicas. (BANKS-LEITE; GALVÂO, 2000, p. 153). 
Em seguida, após suas observaçôes, tira algumas conclusões importantes:

[...] me propunha a conduzi-lo ao uso da fala, determinando o exercício da imitação pela lei imperiosa da necessidade. [...] não se devia contar somente com um trabalho tardio da parte da laringe, eu deveria agir de tal modo que a ativasse com a isca dos objetos necessários às suas necessidades. (BANKS-LEITE; GALVÂO, 2000, p. 158).

O fracasso em tentar introduzir Victor à fala e, mais especificamente, ao uso da língua francesa, que daria a ele a liberdade necessária para entender os modos que organizam o mundo neste momento histórico é bastante evidenciado por Itard, que descreve minuciosamente suas tentativas de aproximar o selvagem do modo civilizado francês do século XIX. Isto ocorria paulatinamente nas escolas francesas, que, aos poucos, excluia o patoá. Este processo de defesa de línguas fortes, por meio de projetos colonizadores, se repetiu nas sucessivas conquistas coloniais na América, África e Ásia.

Como nos aponta Silviano Santiago sobre a colonização da América:

A América transforma-se em cópia, que se quer mais e mais semelhante ao original, quando sua originalidade não se encontraria na cópia do modelo original, mas em sua origem, apagada completamente pelos colonizadores. (SANTIAGO, 2000, p. 14).

O processo colonizador francês e as normas que, obviamente, envolvem o uso da língua francesa, com sua dimensão libertadora e humanizadora, coerente com o ideário da Revolução estão presentes na tentativa normatizadora/normalizadora da linguagem do selvagem de Aveyron, que a considera primitiva, menor, menos desenvolvida:

Creio reconhecer aí, em toda a sua simplicidade, a linguagem de ação, essa linguagem primitiva da espécie humana, originalmente empregada na infância das primeiras sociedades, antes que o trabalho de vários séculos tivesse coordenado o sistema da fala e fornecido ao homem civilizado um fecundo e sublime meio de aperfeiçoamento, que faz desabrochar-lhe o pensamento mesmo em seu berço, e que ele emprega em toda a vida sem apreciar o que é para ele, e o que ele seria sem esse meio se ficasse acidentalmente privado dele, como no caso que nos ocupa. (BANKS-LEITE; GALVÃO, 2000, p. 162).

De toda forma, é importante salientar que esta intenção humanizadora de Itard, ligada à perspectiva do centramento no sujeito moderno acaba por ajudar no desenvolvimento de uma perspectiva educacional que, de alguma forma, desliga-se de uma perspectiva biomédica no sentido da exclusão deste sujeito em espaços onde não seria sequer possível uma tentativa de educação. Entretanto, por outro lado, é também evidente que trata-se de uma inclusão a um processo educacional que, por via do olhar perplexo, como já disse antes, estigmatiza e assujeita este educando a procedimentos com intençóes normatizadoras. Retomando Lígia Assumpção Amaral, que nos ajuda a percorrer este caminho de análise: 
[...] do ponto de vista psíquico, as diferenças significativas jamais passam em 'brancas nuvens': desorganizam, ameaçam, mobilizam. Pois representam aquilo que foge ao esperado, ao simétrico, ao belo, ao eficiente, ao perfeito... (AMARAL, 1994 a, p. 262).

A autora, também partindo de uma análise desde a Psicologia Moderna, observa como, do ponto de vista psicológico, as diferenças causam perplexidade. Aprofundando um pouco a questáo, podemos dizer que esta perplexidade se inscreve por conta dos processos de subjetivação levados a cabo pela colonização dos corpos, pela inscrição na superfície deste corpo do poder: o poder colonizador da escola e da educação. Inicia-se aí, desde Itard e Victor, uma perspectiva educacional voltada à normatização. Daí nasceram os projetos inclusivistas posteriores, e que não são objetos deste ensaio, e o rechaço a iniciativas abertas e menos normatizadoras na Educação de forma geral e na Educação Especial, especificamente.

Itard, então, na sua quinta meta, expõe o que se tornou o grande princípio da educação moderna: o desenvolvimento das funções cognitivas. O século das Luzes trouxe para a Educação um importante - e talvez definitivo, mesmo não sendo o único - objetivo: o desenvolvimento das funções cognitivas. Ao rechaçar as tradiçóes e defender uma posição apolínea e científica para a ciência, a revolução Científica, iniciada no século XVII, propóe:

Sendo um modelo global, a nova racionalidade científica é também um modelo totalitário, na medida em que nega o carácter racional a todas as formas de conhecimento que se não pautarem pelos seus princípios epistemológicos e pelas suas regras metodológicas. Esta é a sua característica fundamental e a que melhor simboliza a ruptura do novo paradigma científico com os que o precedem. [...] Esta preocupação em testemunhar uma ruptura fundante que possibilita uma e só uma forma de conhecimento verdadeiro está bem patente na atitude mental dos protagonistas, no seu espanto perante as próprias descobertas e a extrema e ao mesmo tempo serena arrogância com que se medem os seus contemporâneos. (SANTOS, 2010, p. 21-22).

Como sabe-se, dois destes protagonistas - talvez os mais importantes do ponto de vista ideológico - são Descartes e Bacon, ambos franceses, assim como foi na França que se iniciou o movimento iluminista. Os projetos educacionais das sociedades civilizadas haviam que desenvolver estas capacidades cognitivas, dando aos sujeitos do saber, o poder, pela capacidade analítico-dedutiva, de controlar e prever os fenômenos da natureza. Só é homem (humano) aquele que rechaça a toda forma de tradição e conhecimento da experiência de senso comum, da crença, das artes ou da espiritualidade, só assim se constroi a autonomia do pensamento, que se dá pela via rigorosa da razão.

Sujeitos anormais, com déficits cognitivos jamais chegariam a este patamar. Ao incorporar o jovem Victor ao conjunto de humanos que, por privaçáo de estímulos, não poderia incorporar-se entre as pessoas educadas para e na razão, Itard de 
propóe ao seu grande desafio, de desenvolver uma metodologia que promova sua real inserçáo no mundo dos humanos: que comprove a sua racionalidade. Esta perspectiva deu origem, posteriormente a dois ideários presentes na Educação Especial (mesmo que não sejam exclusivos a esta área): a) a classificação da inteligência, depois desenvolvida no início do século XX, que levou à classificação da deficiência mental (hoje intelectual) em níveis, e b) a ênfase na metodologia, pactuada com o saber médico-clínico, do planejamento individualizado para pessoas com deficiência.

Um desdobramento importante - que vem se desconstruindo, mas que ainda permanece nos dias atuais - é a relaçáo capacidade cognitiva e possibilidade de execuçáo de tarefas que leva à exclusão do espaço de trabalho. Com a industrializaçáo e a divisão técnica do trabalho, estabelecidas no século XIX, ser racional é humano e o lugar dos humanos é o envolvimento com o trabalho. Ainda hoje, a maior dificuldade de inserção no espaço de trabalho, no âmbito dos sujeitos com deficiência, são das pessoas que possuem algum tipo de deficiência intelectual. A gênese deste ideário está presente no trabalho de Itard que, subjetivado por este momento histórico, definiu como meta essencial de educação para o jovem Victor o desenvolvimento de suas capacidades cognitivas, já que, acreditava ele, não haviam sido desenvolvidas porque o "selvagem" esteve privado da estimulação necessária.

Não tive a intenção de desmerecer o importante trabalho de Itard junto ao jovem Victor, em sua tentativa de promover a sua Educação. Só o fato de ter questionado as perspectivas inatistas, propondo uma reflexão sobre o papel da educação, bem como ter rechaçado a violência em seu tratamento são de grande importância. Entretanto, as dizibilidades dizem respeito à uma história vivida e o sentido aqui dado foi de algum tipo de reflexão que propusesse compreender que lugar geográfico-histórico é este em que se ensina um menino "selvagem" desta maneira, que é este corpo "anormal" para o qual é direcionado o "olhar perplexo" (AMARAL, 1994a).

Desta forma, voltamos às questôes iniciais: que pode este corpo? Na racionalidade então construída, e presentificada no trabalho de Itard, a psiquiatrização do corpo (NOGUEIRA, 2015), a monstruosidade do deficiente (AMARAL, 1994b) se instauram. Este corpo de monstro que, sob a égide do saber médico e de um saber educacional com objetivos delimitados ( $\mathrm{O}$ que ensinar a este corpo? $\mathrm{O}$ que ele pode? Por que ele precisa desenvolver sua racionalidade?) é disposto à norma. Ainda na Educação Especial, a avaliação em relação ao típico, as possibilidades de intervenção em relação às capacidades, a ênfase nos aspectos cognitivos são temas presentes. No contemporâneo, mesmo que tenhamos ultrapassado - como, em sua aventura, Itard também ultrapassou - alguns limites de nosso tempo, ainda a Educação Especial é filiada a estas questóes: acredita na resiliência, na norma e na funcionalidade-instrumentalidade da vida.

Assim, como me perguntava no início deste ensaio, se estes foram os espaços de fala evidenciados no trabalho de Itard, dentro de sua proposta pedagógico-médica, muitos espaços de silenciamento deste corpo e de sua corporalidade, entendida como "primitiva", foram mantidos, em favor da manutenção da norma. Devemos nos perguntar até que ponto, ainda, se as perspectivas da Educação Especial proporcionam a construção de devires múltiplos que representam a experiência humana, dentro e 
fora das experiências do viver com deficiência e de que forma nossas propostas metodológicas ainda estão pactuadas com estes ideários aqui elencados.

\section{Referências}

AMARAL, L. A. Corpo desviante/Olhar Perplexo. Psicologia USP, v. 5, n. 1/ 2, p. 245-268, 1994 a.

. Adolescência/Deficiência: uma sexualidade adjetivada. Temas em Psicologia, n. 2, $1994 \mathrm{~b}$. 1998, $221 \mathrm{f}$.

BANKS-LEITE; L.; GALVÃO, I. A Educaçáo de um Selvagem: As experiências pedagógicas de Jean Itard. S. Paulo: Cortez, 2000.

FOUCAULT, M. A ordem do discurso. São Paulo: Loyola, 1996.

HAGÈGE, C. Le Français, histoire d'un combat. Le livre de poche. Paris: Éditions Michel Hagège, 1996.

NOGUEIRA, J. F. A. Discursos de psiquiatrização na educaçáo e governos dos infames da escola: entre cifras de resiliência e acordes de resistência. Tese de Doutorado. Programa de Pós-Graduação em Educação, Universidade Federal do Paraná, 2015. $201 \mathrm{f}$.

SANTIAGO, S. Uma literatura nos trópicos: ensaios sobre dependência cultural. 2 ed. Rio de Janeiro: Rocco, 2000.

SANTOS, B. S. Um discurso sobre as ciências. 7 ed. São Paulo: Cortez, 2010.

\section{Correspondência}

Rafael Siqueira de Guimarães - Universidade Federal do Sul da Bahia, Instituto de Humanidades, Artes e Ciências. Rodovia Itabuna-Ibicaraí, km 39, Ferradas, CEP: 45613-204 - Itabuna, Bahia - Brasil.

E-mail: rafaorlando@gmail.com

Recebido em 03 de junho de 2016

Aprovado em 23 de agosto de 2016 